\title{
The hospital costs associated with acute paediatric burn injuries
}

\author{
E W ter Meulen, ${ }^{1}$ MSc; M J Poley, ${ }^{1,2,3} \mathrm{PhD}, \mathrm{MSc}, \mathrm{LLM}$; M van Dijk, ${ }^{3} \mathrm{PhD}$; A D Rogers, ${ }^{4} \mathrm{MB}$ ChB, FC Plast Surg (SA), MMed; \\ H Rode, ${ }^{5}$ MB ChB, FCS (SA), FRCS, MMed \\ ${ }^{1}$ Institute of Health Policy and Management (iBMG), Erasmus University Rotterdam, The Netherlands \\ ${ }^{2}$ Institute for Medical Technology Assessment (iMTA), Erasmus University Rotterdam, The Netherlands \\ ${ }^{3}$ Intensive Care and Department of Paediatric Surgery, Sophia Children's Hospital, Erasmus MC, Rotterdam, The Netherlands \\ ${ }^{4}$ Ross Tilley Burn Centre, Division of Plastic and Reconstructive Surgery, Sunnybrook Health Sciences Centre, and University of Toronto, Canada \\ ${ }^{5}$ Department of Paediatric Surgery, Red Cross War Memorial Children's Hospital, and Faculty of Health Sciences, University of Cape Town, South Africa
}

Corresponding author: A Rogers (alandavid.rogers@sunnybrook.ca)

Background. Ongoing rationing of healthcare threatens services that are well established, and cripples others that desperately require investment. Burn, for one, remains a neglected epidemic in South Africa (SA), despite the magnitude of the problem.

Objective. To identify the prominent components contributing to the cost of hospital admission with paediatric burn injury. Determining the true costs of specialist services is important, so that resources can be allocated appropriately to achieve the greatest possible impact. Methods. A retrospective study was undertaken over 1 year to determine patient demographics and injury details of 987 patients admitted with burn injuries to Red Cross War Memorial Children's Hospital, Cape Town, SA. The in-hospital financial records of 80 randomly selected patients were examined. This was followed by a prospective study to determine the financial implications of four cost drivers, i.e. bed cost per day, costs of medications received, costs of dressings for wound care, and costs of surgical intervention. A random selection of 37 dressing changes (in 31 paediatric patients) and 19 surgical interventions was observed, during which all costs were recorded.

Results. As expected, severe flame burns are responsible for more prolonged hospital stays and usually require surgical intervention. Scald burns comprise the greatest proportion of burn injuries, and therefore account for a considerable part of the hospital's expenditure towards burn care.

Conclusion. While community programmes aiming to prevent burn injuries are important, this study motivates for the implementation of accessible ambulatory services in low-income areas. This strategy would enable the burn unit to reduce its costs by limiting unnecessary admissions, and prioritising its resources for those with more severe burn injuries.

S Afr Med J 2016;106(11):1120-1124. DOI:10.7196/SAMJ.2016.v106i11.11202

The establishment of a burn unit or a burn centre represents a major commitment of hospital resources. ${ }^{[1-4]}$ To fulfil its mandate to provide optimal, holistic care to patients with burns and complex wounds, it requires dedicated, multidisciplinary specialist personnel and well-equipped facilities. To date, no studies have been undertaken to investigate the true cost of managing paediatric burn injuries and their sequelae in South Africa (SA).

Managing a major burn is initially an intense, goal-directed undertaking. Priorities include effective resuscitation, early excision and autografting, attentive wound care and nutrition, and prevention and treatment of complications (notably, these patients are especially susceptible to infections in the acute phase of care and contractures during rehabilitation). Psychosocial and physical rehabilitation and reconstruction may be necessary for several years after the injury. Burn survivors require concerted investment of multidisciplinary resources, services and facilities to successfully transition through this complex process.

Determining the true costs of a specialist service is important, particularly in light of the considerable rationing of healthcare budgets and resources in SA. Understanding these costs will enable hospital managers, preferably after discussion with senior clinicians, to allocate health resources appropriately to achieve the greatest possible impact. For instance, considerable cost savings may be realised, in the context of burn care, by using some expensive dressing materials, applied in an ambulatory setting twice weekly, rather than by admitting the same patient for daily dressing changes in the burn unit. Determining which patients would truly benefit from such a strategy is clearly within the scope of the burn surgeon's discretion (by considering the extent, depth and aetiology of the burn injury, as well as psychosocial factors), but cost benefits will not be realised if hospital administrators limit access to the more expensive dressing modality without considering the considerable cost savings that can be obtained by use of such a strategy. ${ }^{[1-6]}$

The purpose of this study was to determine the major cost drivers of managing an acute paediatric burn injury at a specialist paediatric burn unit. The anticipated lifetime implications (physical, psychological and financial) of these injuries are beyond the scope of the study.

\section{Methods}

A retrospective study was undertaken over a 1-year period (October 2013 - September 2014) to determine patient demographics. This was followed by a prospective study to determine the financial implications of four a priori cost drivers, i.e. bed cost per day, medications received, costs of dressings for wound care, and costs of surgical intervention. ${ }^{[1,4,5,7-9]}$

Chart reviews were undertaken of 80 patients' clinical and financial records of admission with a burn injury at Red Cross War Memorial Children's Hospital, Cape Town, SA. A random selection of 37 dressing changes (in 31 children) and 19 surgical interventions was observed, during which all itemised costs were recorded. Data were then transferred to a comprehensive proforma to facilitate analysis. This information 
permitted the extrapolation of the costs of the various individual items and interventions. ${ }^{[9]}$ Only direct medical costs, associated with the acute burn injury from hospital admission to discharge, were calculated, and these were expressed in SA rand (ZAR). Standard provincial fiscal reference values (Uniform Patient Fee Schedule, categories 20;14) were used to calculate the monetary implications of treating burns in paediatric patients. Patients were divided into two groups $(<4$ years and $>4$ years of age) to account for and compare the financial implications of different physiological, anatomical and aetiological considerations.

Excluded from the analysis were patients with incomplete data, ambulatory patients, those with concomitant trauma, those who were readmitted, and those who died during the admission. Personnel salaries were not considered for this study, because although these account for considerable hospital and provincial expenditure, the costs continue over the intermediate to long term irrespective of bed occupancy in the burn unit. Such costs are also supposedly incorporated into hospital bed costs.

Descriptive statistics, and univariate and multivariate regressions were performed to identify the most significant cost determinants, and a sensitivity analysis was undertaken to explore the impact of uncertainty on the results and conclusions of the evaluation. Mann-Whitney and KruskalWallis tests were applied to measure the significance of differences in resource consumption and costs between subgroups and to evaluate the impact of total body surface area (TBSA) on cost. Regression analysis was performed to analyse the impact of cost drivers such as age, sex, aetiology and TBSA burned on total costs.

Institutional research ethical permission was obtained (HREC: 670/2014) for this study.

\section{Results}

The Red Cross War Memorial Children's Hospital budget for the 2014 financial year was ZAR635 697 million, of which ZAR14 033 million (2.2\%) was allocated for burn care.

A total of 987 patients were admitted over the 12-month period of retrospective study. One hundred and three (10\%) of these were excluded owing to incomplete clinical and financial records; 884 (90\%) charts were therefore available for study. These were divided according to age (patients $\leq 4$ and $>4$ years) (Table 1). The mean age of these patients on admission was 3.1 years, with $75 \%<4$ years old. Male patients predominated, and the mean burn size was $8 \%$ TBSA. Almost two-thirds of patients sustained burns of $<10 \%$ TBSA, and $74 \%$ of burns resulted from scalds, although flame burns and more extensive burns were more prevalent in older paediatric patients.

Overall, the mean length of stay (LOS) was 5.6 days, ranging from 4.9 days for patients $<4$ years of age to 7.4 days for those $>4$ years old ( $p=0.042)$. Patients with flame burns had considerably longer hospital stays than those with scald injuries (14.6 v. 5.3 days; $p<0.001$ ). In patients with burns involving $<10 \%$ TBSA, the hospital LOS was 3.8 days compared with a mean of 48.8 days for burns $>30 \%$ TBSA (Table 2).

Individual medication charts from 80 inpatient records were scrutinised (Table 3).

Table 1. Clinical and demographic characteristics of patients admitted with burn injury (October 2013 - November 2014)

\begin{tabular}{|c|c|c|}
\hline Clinical and demographic characteristics & Sample, $n(\%)$ & Mean \\
\hline \multicolumn{3}{|l|}{ Sex } \\
\hline Boys & $497(56)$ & - \\
\hline Girls & $386(44)$ & - \\
\hline \multicolumn{3}{|l|}{ Age $(n=877)$, years } \\
\hline$\leq 4$ & $654(75)$ & 1.7 \\
\hline$>4$ & $223(25)$ & 7.1 \\
\hline \multicolumn{3}{|l|}{ TBSA ( $n=619), \%$} \\
\hline $1-10$ & $556(77)$ & 5.2 \\
\hline $11-20$ & $129(18)$ & 14.3 \\
\hline $21-30$ & $23(3)$ & 24.9 \\
\hline$>30$ & $11(2)$ & 40.2 \\
\hline \multicolumn{3}{|l|}{ Aetiology $(n=827)$} \\
\hline Scald & $613(74)$ & - \\
\hline Flame & $72(9)$ & - \\
\hline Electrical & $27(4)$ & - \\
\hline Unknown & $115(13)$ & - \\
\hline \multicolumn{3}{|l|}{ Payer $^{\star}(n=833)$} \\
\hline $\mathrm{H} 1$ & $741(85)$ & - \\
\hline $\mathrm{H} 2$ & $69(8)$ & - \\
\hline $\mathrm{H} 3$ & $23(3)$ & - \\
\hline
\end{tabular}

Table 2. Length of stay of patients admitted with burn injury (October 2013 November 2014)

\begin{tabular}{|c|c|c|c|c|}
\hline Patient category & Patients, $n$ & $\begin{array}{l}\text { Length of stay } \\
\text { (days), mean (SD) }\end{array}$ & $\begin{array}{l}\text { Length of stay } \\
\text { (days), range }\end{array}$ & $p$-value \\
\hline Entire group & 877 & $5.6(10.0)$ & $0-137$ & Not applicable \\
\hline Age (years) & & & & 0.042 \\
\hline$\leq 4$ & 654 & $4.9(6.8)$ & $0-66$ & \\
\hline$>4$ & 223 & $7.4(16.1)$ & $0-137$ & \\
\hline Aetiology & & & & $<0.001$ \\
\hline Scald & 613 & $5.3(7.5)$ & $0-92$ & \\
\hline Flame & 72 & $14.6(24.9)$ & $0-137$ & \\
\hline TBSA (\%) & & & & $<0.001$ \\
\hline $1-10$ & 556 & $3.8(5.0)$ & $0-58$ & \\
\hline $11-20$ & 129 & $9.4(8.0)$ & $0-66$ & \\
\hline $1-30$ & 23 & $23.3(17.4)$ & $10-92$ & \\
\hline 30 & 11 & $48.8(47.7)$ & $0-137$ & \\
\hline
\end{tabular}


Seventeen different pharmaceutical agents were administered, but only the four most frequently administered were recorded. Paracetamol and gabapentin were most commonly prescribed and administered.

Dressing changes were noted in 31 patients, the frequency of which varied from daily to once a week, depending on the discretion of the burn surgeon, nature of the dressing applied, extent and depth of the wound, and presence or absence of infection. The mean interval between dressing changes was 2 days, and more frequent dressings were performed in cases of flame burns and large burns $(p<0.001)$. There was an indication that flame burns required a greater mean total number of dressings than scalds $(p<0.063)$. Burn wounds $<10 \%$ TBSA required a mean of 1.2 dressing changes during admission (standard deviation (SD) 1.8), those between $11 \%$ and 20\% TBSA 3.2 (SD 2.9), those between $21 \%$ and $30 \%$ TBSA 8.1 (SD 7.1), and those with $>30 \%$ TBSA 18.8 (SD 18.9), respectively. The cost of dressing changes performed in the burn unit was ZAR441 per $1 \%$ TBSA and ZAR608 per $1 \%$ TBSA if undertaken in the operating room. The mean total cost per patient for dressing changes was ZAR1 900.

Thirty-two percent $(n=285)$ of patients admitted for burn injuries were operated on at least once, with the majority (78\%) undergoing debridement and autografting. The older patient category was considerably more likely to require surgical intervention $(p<0.001)$. Scalds were operated on average 0.4 (range 0 - 14) times, whereas flame burns required a mean of 2.1 (range $0-23$ ) procedures per person $(p=0.001)$. Burns $<10 \%$ TBSA required 0.3 (SD 0.6) procedures, those between $11 \%$ and $20 \%$ required 0.7 (SD 0.9), those between $21 \%$ and $30 \%$ required 2.2 (SD 3.5), and those $>30 \%$ required 7.7 (SD 7.3) during their hospital admission $(p=0.001)$. The significance of the anatomical site of surgery was not determined. Extrapolated from the detailed information obtained from 30 patients assessed during surgery, it was calculated that the cost for those who underwent surgery was ZAR31 037 compared with ZAR6 605 for those treated conservatively (i.e. without surgery).

Fig. 1 depicts the relationship between total cost and TBSA. A wide variation in costs is noted for patients with large burns. Although there were notable outliers, the curve generally has a slow upward gradient for burns $<20-25 \%$ TBSA and an exponential increase in cost per body surface area for larger burns. The mean total cost of treatment was ZAR15 231 per patient (Table 4). Costs associated with hospitali-

\begin{tabular}{|c|c|c|c|c|}
\hline Medication & Patients, $n(\%)$ & Mean (SD) & $\begin{array}{l}\text { Minimum } \\
\text { cost (ZAR) }\end{array}$ & $\begin{array}{l}\text { Maximum } \\
\text { cost (ZAR) }\end{array}$ \\
\hline Paracetamol (mg) & $80(100)$ & $5.3(7.9)$ & 12 & 39.9 \\
\hline Gabapentin (mg) & $72(90)$ & $1.1(1.8)$ & 0 & 11.9 \\
\hline Valoron (2.5 mg drops) & $50(63)$ & $62(109.0)$ & 0 & 720 \\
\hline Multivitamins (mL) & 37 & $32(60.0)$ & 0 & 370 \\
\hline
\end{tabular}

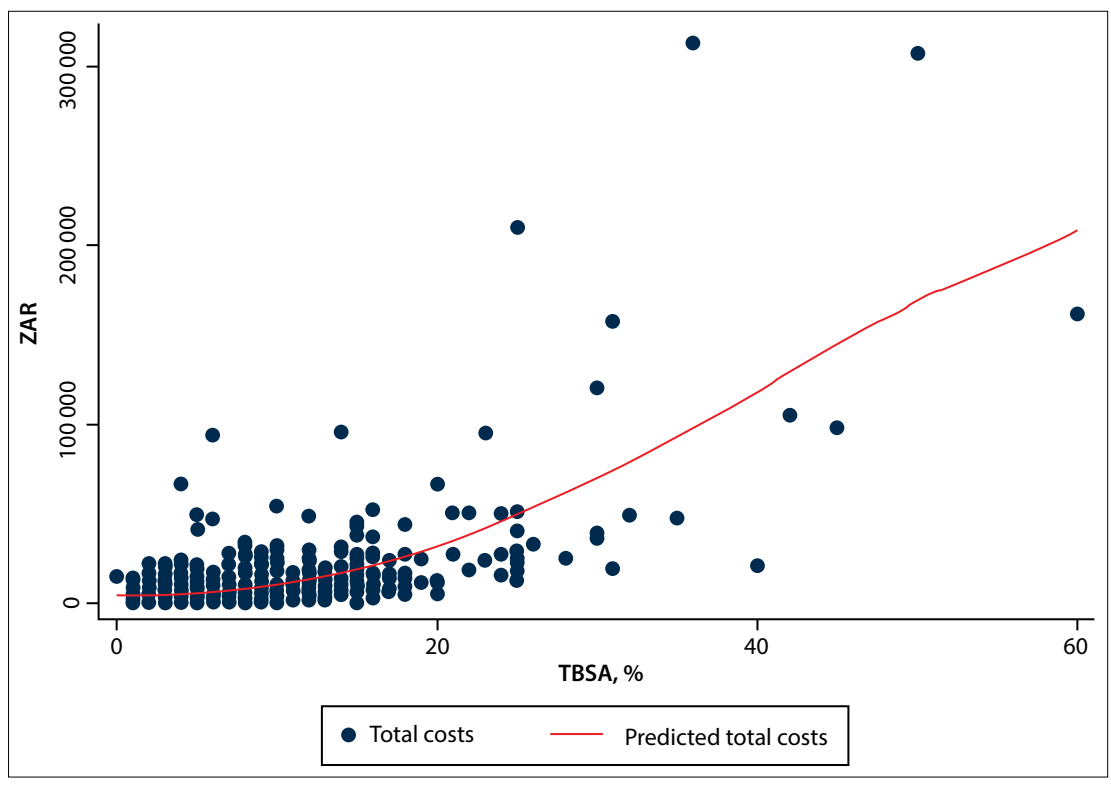

Fig. 1. Total costs and predicted costs (ZAR) v. TBSA.

sation - cost of occupying a hospital bed - accounted for $62 \%$ and surgery for $21 \%$. For the majority (95\%) of patients the cost was <ZAR50 000, with a median hospital cost of ZAR7 332 per patient. Substantial differences in costs were noted depending on subgroup, highlighting the varied nature of burn wounds and their required management. Typically, older paediatric patients, patients with flame burns, and those with large TBSA burns incurred the greatest financial costs.

Multiple linear regression analyses determining relevant cost drivers showed the impact of different variables (age, sex, aetiology and TBSA) on cost per component and on total costs. Table 5 shows the unstandardised coefficients and their significance. Although age appears to have a positive effect on total costs, and male sex a negative influence, neither variable reaches significance ( $p=0.7$ and $p=0.2$, respectively). TBSA had a significant $(p<0.01)$ effect on total costs. Mann-Whitney tests confirmed the findings in regression analysis. Flame burns and increasing TBSA $(p<0.001)$ had a positive effect on costs of surgery and hospital LOS $(p<0.01)$.

\section{Discussion}

The purpose of this study was to determine the magnitude of the main factors contributing to the cost of paediatric patients admitted for burns. These cost drivers were identified a priori as length of hospitalisation (the hospital bed), operative costs, wound care dressings, most frequently used pharmaceuticals and staff renumeration. ${ }^{[1]}$ Various methods have been used to calculate the cost of burn care in other studies. ${ }^{[1-3,5,7]}$ They are either retrospective or prospective in design, and based on hospital coding and expenditure records, patient billing, diagnostic categories, actual individual item counts, records of observed activity or prospective data collection. Retrospective data collections are laborious and frequently lack consistency as a result of poor documentation. Prospective data collection facilitates greater accuracy and reliability, but requires considerable planning to achieve effectiveness and demonstrate applicability. We have used a retrospective and a prospective method for the purposes of this study. The former was used to obtain patient demographics over a year, and the latter to evaluate medicine consumption, theatre activity and dressing costs. 
Table 4. Mean component costs and total costs per patient, 2014

\begin{tabular}{|c|c|c|c|c|c|}
\hline Patient category & $\begin{array}{l}\text { Cost of hospital days } \\
\text { (ZAR), mean (SD) }\end{array}$ & $\begin{array}{l}\text { Cost of medication } \\
\text { (ZAR), mean (SD) }\end{array}$ & $\begin{array}{l}\text { Cost of dressings } \\
\text { (ZAR), mean (SD) }\end{array}$ & $\begin{array}{l}\text { Cost of surgery } \\
\text { (ZAR), mean (SD) }\end{array}$ & $\begin{array}{l}\text { Total cost (ZAR), } \\
\text { mean (SD) }\end{array}$ \\
\hline Overall (100\%) & 9429 (16 885) & $203(555)$ & $1900(6582)$ & 2866 (6 375) & $15231(30009)$ \\
\hline \multicolumn{6}{|l|}{ Age (years) } \\
\hline$\leq 4(75 \%)$ & $8251\left(\begin{array}{lll}11 & 374)\end{array}\right.$ & $114(162)$ & $1392(2841)$ & 2182 (4 389) & $12641(17365)$ \\
\hline$>4(25 \%)$ & 13071 (27 089) & $466\left(\begin{array}{ll}1 & 022\end{array}\right)$ & $3519(12321)$ & 4854 (9 971) & 23395 (52 087) \\
\hline \multicolumn{6}{|l|}{ Aetiology } \\
\hline Scald (74\%) & $8946(12544)$ & $160(269)$ & $1563(3572)$ & $2259(4790)$ & $13118(19635)$ \\
\hline Flame (9\%) & $24570(41841)$ & $762(1635)$ & $7654(20102)$ & $9670(14528)$ & $472234(80427)$ \\
\hline Other (17\%) & 5915 (7 512) & $146(227)$ & $657(693)$ & 2002 (3 935) & $9678(10718)$ \\
\hline \multicolumn{6}{|l|}{ TBSA (\%) } \\
\hline $1-10(77 \%)$ & $6466(8453)$ & $123(205)$ & $758(972)$ & $1644(3572)$ & 8998 (1 759) \\
\hline $11-20(18 \%)$ & $15719(13456)$ & $324(334)$ & 2532 (2 197) & $3828(6262)$ & 22394 (18 999) \\
\hline $21-30(3 \%)$ & $39078(29310)$ & $721(758)$ & $10147(10582)$ & $10712(13936)$ & 60658 (52 909) \\
\hline$>30(2 \%)$ & 82015 (80 201) & $2846(3426)$ & $34932(36224)$ & $29598(23$ 137) & $161262(136076)$ \\
\hline
\end{tabular}

Staff remuneration was not included as a separate entity, as this is theoretically included in the costs of the operative interventions and hospital stays. ${ }^{[1]}$ At the time of writing (2015), annual remuneration for a registered nurse was ZAR435 000, for a registrar-in-training ZAR780 000, and for a consultant ZAR960 000. A bed in a general ward cost ZAR1 680, in a high-care unit ZAR3 622 and in an intensive care unit ZAR7 668 per day.

The total costs of burn injuries were influenced by treatment components, which in turn were influenced by patient demographics and clinical characteristics. Age, sex, severity and cause influenced the main cost components of LOS, medication, dressings and surgery. The estimated average cost of treating a burn was ZAR13 790. This figure is considerably higher for those with burns $>20-25 \%$ TBSA, with an exponential increase as the percentage TBSA increases. ${ }^{[1]}$ A patient with a major burn requires more surgery, dressing changes, and medications, and also has a longer hospital stay (between 1 and 3 days per percentage burn) and a greater likelihood of complications during treatment. In this study, a single operative intervention was noted to increase the mean overall cost by $47 \%$.

The patient demographic profile was similar to that in previous studies from SA and elsewhere. ${ }^{[10-14]}$ Sixty-five percent were males, and scald injuries predominated. Eighty-five percent of patients were in the lowest socioeconomic category, denoting that they would not be expected to pay for health services. These patients often reside in a low-income environment, with very

Table 5. Regression coefficients on component costs and total costs

\begin{tabular}{llllll}
\hline $\begin{array}{l}\text { Patient } \\
\text { category }\end{array}$ & $\begin{array}{l}\text { Cost of hospital } \\
\text { days (ZAR) }\end{array}$ & $\begin{array}{l}\text { Cost of } \\
\text { medication } \\
(\text { ZAR) }\end{array}$ & $\begin{array}{l}\text { Cost of } \\
\text { dressings } \\
\text { (ZAR) }\end{array}$ & $\begin{array}{l}\text { Cost of } \\
\text { surgery } \\
\text { (ZAR) }\end{array}$ & $\begin{array}{l}\text { Total cost } \\
\text { (ZAR) }\end{array}$ \\
\hline Age & -107 & $33^{*}$ & 59 & 86 & 170 \\
Sex & -1399 & 60 & $-908^{+}$ & -79 & -2176 \\
Flame burns & $17043^{*}$ & -64 & $4887^{*}$ & $6619^{*}$ & $28654^{*}$ \\
TBSA & $1568^{*}$ & $25^{*}$ & $582^{*}$ & $501^{*}$ & $2751^{*}$ \\
$\mathrm{R}^{2}$ & 0.42 & 0.37 & 0.41 & 0.35 & 0.46 \\
$\begin{array}{l}* \text { Significant alpha } 0.01 . \\
\text { 'Significant alpha } 0.05 .\end{array}$ & & & &
\end{tabular}

limited facilities for either ambulatory or aftercare, placing a greater strain on hospital facilities. Children $<4$ years of age (and especially those $<1$ year of age) were more likely to require hospitalisation for their treatment and accounted for $68 \%$ of hospital stays and $39 \%$ of the total cost of burn care. The majority of patients, however, presented with small partial-thickness burns, and only 32\% required surgery, with a third undergoing more than one procedure. Patients with flame burns required hospital stays in excess of three times those who had sustained scald injuries.

TBSA involved in the burn injury had an important influence on period of hospitalisation, number of surgical interventions, dressing changes, and cost of medications. These findings are consistent with published work. ${ }^{[1-8]}$ The hospital bed occupation was responsible for $62 \%$ of the cost and correlated with burn size, but not with anatomical site of the burn. ${ }^{[2]}$ Paediatric patients with scalds stayed three times shorter in hospital, required less medication, received fewer dressing changes and were four times less likely to require surgery than those with flame burn injuries. Severe burns and flame burns directly and independently increase the costs by increasing dressing changes, medications and surgical requirements. A higher percentage of flame burns (9\%) include burns greater than 30\% TBSA; this proportion was only $1 \%$ in the scald burn group. The relationship between total costs and TBSA is positive and exponential. After predicting values from a regression analysis, the relation between TBSA and total costs is almost linear.

As with many of the cost drivers, the cost of medications was possibly a considerable underestimation at ZAR203 per day on average. Dressing changes were the third most expensive cost driver - possibly a gross underestimation. The research showed an intuitive and positive correlation between TBSA and the number of dressing changes, with an average cost of ZAR121 per percentage burn. Early 
excision and grafting has become the standard of care for deep burns; numerous authors have attested to its value to reduce hospital stay and complications. Surgical cost was on average ZAR5 820 per operation, or ZAR119 per minute. The costs per minute quoted in this article are only slightly higher than those in other published work, confirming the reliability of these costs within this context. ${ }^{[5]}$

External validity is limited, as this study was undertaken at a single, dedicated paediatric facility. Cost comparison with other published paediatric burn data may be difficult, as patient populations differ, inclusion criteria vary, and financial resource allocation depends on the broader economic context. The patients in our study varied from those with minor burns requiring brief hospital stays and only one dressing change to major complicated burns requiring multiple operative procedures and lengthy hospital stays. It was not unexpected that LOS was influenced by the age of the patient, aetiological factors, TBSA and depth of the burn.

Patients with burns, especially in the paediatric population, may require ongoing physical rehabilitation and psychological therapy for many years after the injury, and the disruptions to the patient and those in the patient's larger support structure are challenging to enumerate financially. Direct healthcare costs may represent only $20 \%$ of the long-term financial burden on the patient and their family. ${ }^{[7]}$ Prehospital costs could not be included, and we also excluded patients admitted and discharged from the emergency department. The care of these patients usually involves dressing changes performed in the ambulatory setting, and places minimal strain on hospital resources, unless the patient is later admitted for surgery or with a complication.

Although every effort was made to obtain all the information for the acute treatment period, considerable challenges were identified with both the clinical and administrative records. These were variably complete, handwriting was sometimes illegible, and financial records were frequently incomplete. An estimated $2 \%$ of documentation was absent. Poor record-keeping is a common clinical problem encountered in regional government hospitals and a major challenge for those undertaking retrospective research ${ }^{[3,4]}$ Fortunately, the cost of hospitalisation and theatre times could be calculated prospectively with accuracy. Not all cost prices for dressings were available from the local pharmacy and financial departments, resulting in prices being obtained from the internet, which possibly led to an underestimation of the final costs.

The Consensus Report on Revitalising Clinical Research in SA of the Academy of Science of South Africa (ASSAf) identified the low level of investment in clinical research as a major factor in SA's declining clinical research performance. ${ }^{[14]}$ This is the first SA study to focus on healthcare resource utilisation for hospitalised paediatric burn survivors. Such research is essential to evaluate current management policies and identify new healthcare strategies, with the objective of reducing costs while maintaining good clinical practice. It is important to emphasise that this study was undertaken in the context of a tertiary service striving to maintain developed world standards of clinical care with constant budgetary threats. ${ }^{[5,8,12,14]}$ Burn surgery, which should be regarded as a subspecialty clinical service, controlled centrally at tertiary or even quaternary level, but with ready lines of communication and referral to and from primary and secondary levels of care, have had to compete fiscally with numerous primary care priorities, notably maternal and child health, other trauma and infectious diseases. ${ }^{[11,14]}$

Eighty-five percent of patients included in this study were from the lowest socioeconomic category, which has been associated with worse health status and increased susceptibility to injury and hospitalisation, lower standards of healthcare provision, greater complications, and increased costs. ${ }^{[2,15]}$ Efforts to upgrade the facilities and access to emergency care will also contribute to reduced severity of the burn and decrease the cost associated with burn injuries independently because of reduced pressure for bed admission over more sustainable ambulatory care. ${ }^{[12,16]}$

To diminish the considerable hospital expenditure of burn injury, especially minor scalds injuries, a substantive shift from standard hospital care towards the use of long-acting topical dressings, early excision and skin grafting for deep burns, day surgery and ambulatory care is required. ${ }^{[8]} \mathrm{SA}$ research has shown that considerable savings can be achieved by using modern burn wound management strategies. ${ }^{[5,12]}$ To truly reduce the burden of thermal injuries, however, community-based intervention programmes, especially those focusing on product design, legislation, and firstaid education programmes, could reduce the incidence by up to $80 \%$ in the years following their introduction. ${ }^{[1,11,17,18]}$ Endeavours such as these would amount to a fraction of the cost of managing burn injuries in a hospital setting, but would require the concerted participation of local, regional and national government.

\section{Conclusion}

This study seeks to establish the relative contributions, during the paediatric burn survivor's admission for acute care of burn injury, of hospital bed occupation, medication, dressing changes and surgery. Hospital bed occupation accounted for $59 \%$ of the cost, and surgery was the next most expensive aspect of care. The aetiology of the burn injury and the extent of the burn correlated significantly with costs incurred.

There is an enormous need to reduce the incidence of preventable trauma, such as burn injury in SA, not least because managing burn injury effectively is a major investment of multidisciplinary resources and expertise. Despite reinforcing the application of evidence-based modern burn care strategies for patients with major burns requiring admission, this study advocates for the more effective introduction of community-based ambulatory burn care systems to reduce the financial burden on the public health system of minor scald injuries.

1. Ahn CS, Maitz PK. The true cost of burn. Burns 2012;38(7):967-997. DOI:10.1016/j.burns.2012.05.016 2. Klein MB, Hollingworth W, Rivara FP, et al. Hospital costs sssociated with pediatric burn injury. J Burn Care Res 2008;29(4):632-637. DOI:10.1097/BCR.0b013e31817db951

Shields BJ, Comstock RD, Fernandez SA, et al. Healthcare resource utilization and epidemiology of pediatric burn-associated hospitalizations, United States, 2000. J Burn Care Res 2007;28(6):811-826. DOI:10.1097/bcr.0b013e3181599b51

4. Pellatt RAF, Williams A, Wright H, Young AER. The cost of a major paediatric burn. Burns 2010;36(8):1208-1214. DOI:10.1016/j.burns.2010.04.008

5. Allorto NL, Clarke DL, Thomson SR. A cost model case comparison of current versus modern Allorto NL, Clarke DL, Thomson SR. A cost model case comparison of current versus modern
management of burns at a regional hospital in South Africa. Burns 2011;37(6):1033-1037. DOI:10.1016/j. marn.2011.04.004

6. Cox SG, Cullingworth L, Rode H. Treatment of paediatric burns with nanocrystalline silver dressing compared with standard wound care in a burns unit: A cost analysis. S Afr Med J 2011;101(10):728-731. Sanchez JL, Pereperez SB, Bastida JP, Martinez MM. Cost-utility analysis applied to the treatment of burn patients in a specialized center. Arch Surg 2007;142(1):50-57. DOI:10.1001/archsurg.142.1.50

8. Mandal A. Quality and cost-effectiveness - effects in burn care. Burns 2007;33(4):414-417. DOI:10.1016/j. burns.2006.08.035

9. Hemington-Gorse SJ, Potokar TS, Drew PJ, Dickson WA. Burn care costing: The Welsh experience Burns 2009;35(3):378-382. DOI:10.1016/j.burn.2008.08.012

10. Koç Z, Saqlam Z. Burn epidemiology and cost of medication in paediatric burn patients. Burns 2012;38(6):813-819. DOI:10.1016/.j.burns.2012.03.011

11. Rode H, Cox S, Nomanoglu A, Berg AM. Burn care in South Africa: A micro cosmos of Africa. Pediatr Surg Int 2014;30(7):699-706. DOI:10.1007/s00383-014-3519-5

2. Cox Cox SG, Martinez R, Glick A, Numanoglu A, Rode H. A review of community maty
paediatric burn wounds. Burns 2015;41(8):1805-1810. DOI:10.1016/j burns.2015.05.024

13. Van Niekerk A, Rode H, Laflamme L. Incidence and patterns of childhood burn injuries in the Western
a Van Niekerk A, Rode H, Laflamme L. Incidence and patterns of childhood burn inju
Cape, South Africa. Burns 2004;30(4):341-347. DOI:10.1016/j.burns.2003.12.014

14. Paruk F, Blackburn JM, Friedman IB, Mayosi BM. National expenditure on health research in South Africa: What is the benchmark? S Afr Med J 2014;104(7):468-474. DOI:10.7196/samj.6578

15. Rhee P, Grossman D, Rivara FP, et al. The effect of payer status on utilization of hospital resources in trauma care. Arch Surg 1997;132(4):399-404.DOI:10.1001/archsurg.1997.01430280073010.

6. Rode H, Rogers AD, Numanoglu A, et al. A review of primary and secondary burn services in the Western Cape, South Africa. S Afr Med J 2015;105(10):853-857. DOI:10.7196/SAMJnew.8187

17. Liao C, Rossignol AM. Landmarks in burn prevention. Burns 2000;26(5):422-434. DOI:10.1016 s0305-4179(00)00026-7

18. Parbhoo A, Louw QA, Grimmer-Somers K. Burn prevention programs for children in developing countries require urgent attention: A targeted literature review. Burns 2010;36(2):164-175. DOI:10.1016/j burns.2009.06.215

Accepted 29 June 2016. 